\title{
Determining Hazards' Prevention Critical Control Points in Water Supply Systems ${ }^{+}$
}

\author{
Stavroula Tsitsifli * and Vasilis Kanakoudis \\ Civil Engineering Department, University of Thessaly, 38221 Volos, Greece; tsitsifli@uth.gr (S.T.); \\ bkanakoud@uth.gr (V.K.) \\ * Correspondence: tsitsifli@uth.gr; Tel.: +30-2421-074-178 \\ + Presented at the 4th EWaS International Conference: Valuing the Water, Carbon, Ecological Footprints of \\ Human Activities, Online, 24-27 June 2020.
}

Published: 5 September 2020

\begin{abstract}
A drinking water supply system is an extraordinarily complex system-consisting of kilometers of pipes and various tanks, valves, pumps, and other equipment. This complexity makes it extremely vulnerable to physical, chemical, and/or biological hazards. Therefore, the vulnerability assessment of a drinking water supply system to identify the critical control points is absolutely necessary. This paper assesses the vulnerability of the drinking water supply systems. The assessment is elaborated in systems using water from surface water bodies and groundwater bodies. The critical control points are identified using a risk assessment methodology (identifying the probability of the hazard occurrence and its effect or severity) where the monitoring parameters, and the corrective actions are determined.
\end{abstract}

Keywords: drinking water; hazards; critical control points; water supply systems

\section{Introduction}

Drinking water safety is of paramount importance for public health. Drinking water supply systems (WSSs) are very complex systems, therefore, it is important to identify all possible hazards and establish a system to control the critical points. Nowadays, preventive systems and risk-based approaches to assess and manage the risks and hazardous events across the entire water supply network, from the water source to the final point of consumption, must be implemented to guarantee a reliable supply of safe drinking water [1,2]. For that purpose, various tools and strategies have been developed, such as Hazard Analysis and Critical Control Point (HACCP) and Water Safety Plans (WSPs) [2]. Different water origin (surface water, groundwater, springs, desalination water) and different physicochemical and microbiological characteristics are factors affecting drinking water safety. Many hazards exist alongside the water supply system from water catchments and sources to the storage reservoirs, the water treatment facilities and the distribution system [3].

Drinking water hazards can be classified to physical, chemical, microbiological and radiological ones. Physical hazards can cause water contamination, due to their impact to the physical appearance or properties of water. Presence of sediment, suspended organic material, wood, glass, metal, plastic and stones are considered physical hazards [2]. Chemical hazards can be caused by naturally occurring chemicals, chemicals from industrial sources and human dwellings, chemicals from agricultural activities and chemicals used in water treatment or from materials in contact with drinking water $[1,2]$. When the concentrations of inorganic or organic chemical compounds found in the water exceed their maximum allowable parametric values, they can cause health problems. For example, the concentrations of disinfection-by-products formed during the water disinfection process, are accused of serious health problems, such as cancer [4,5]. Pathogenic microorganisms contaminating drinking water are waterborne or water-based, depending on their origin [6]. 
According to Reynolds et al. [6], while waterborne pathogens are excreted in the feces of humans and transmitted via ingestion, water-based ones occur naturally in the water and are not usually transmitted from person to person. Waterborne pathogens include Norovirus G1 and G2, Rotavirus A, Shigella sonnei, Helicobacter, Cryptosporidium hominis, etc. [7]. Known water-based pathogens are Legionella pneumophila, Nontuberculous mycobacteria, Pseudomonas aeruginosa, etc. [7]. Radiological hazards are due to naturally occurring or human-made radioactive substances in drinking water [2].

\section{Vulnerability Assessment and Hazard Identification in Water Supply Systems}

To assess the vulnerability of the water supply system, a flow diagram is necessary (Figure 1). A typical water supply system is described. Water is abstracted from groundwater sources or surface water intake points. For simplicity reasons, desalination water sources are not taken into consideration in this study. Then, water is taken through a pipe transmission network to water reservoirs for storage, and then it is directed to the water treatment plant, where pretreatment and treatment take place. In the case of surface water, water treatment consists of various stages, such as coagulation, flocculation, sedimentation, filtration, ozonation, and absorption. The process depends on the water characteristics and cannot be generalized. Groundwater usually undergoes a simpler water treatment process, if necessary - which always depends on the water characteristics. After water treatment, water is taken to reservoirs where disinfection usually takes place to inactivate any pathogenic microorganisms. Water is then transferred to the consumers' taps through the distribution network, consisting of pipes, valves, pumps, etc. Each water supply network is different, depending on the water quality and the particular characteristics of each network.

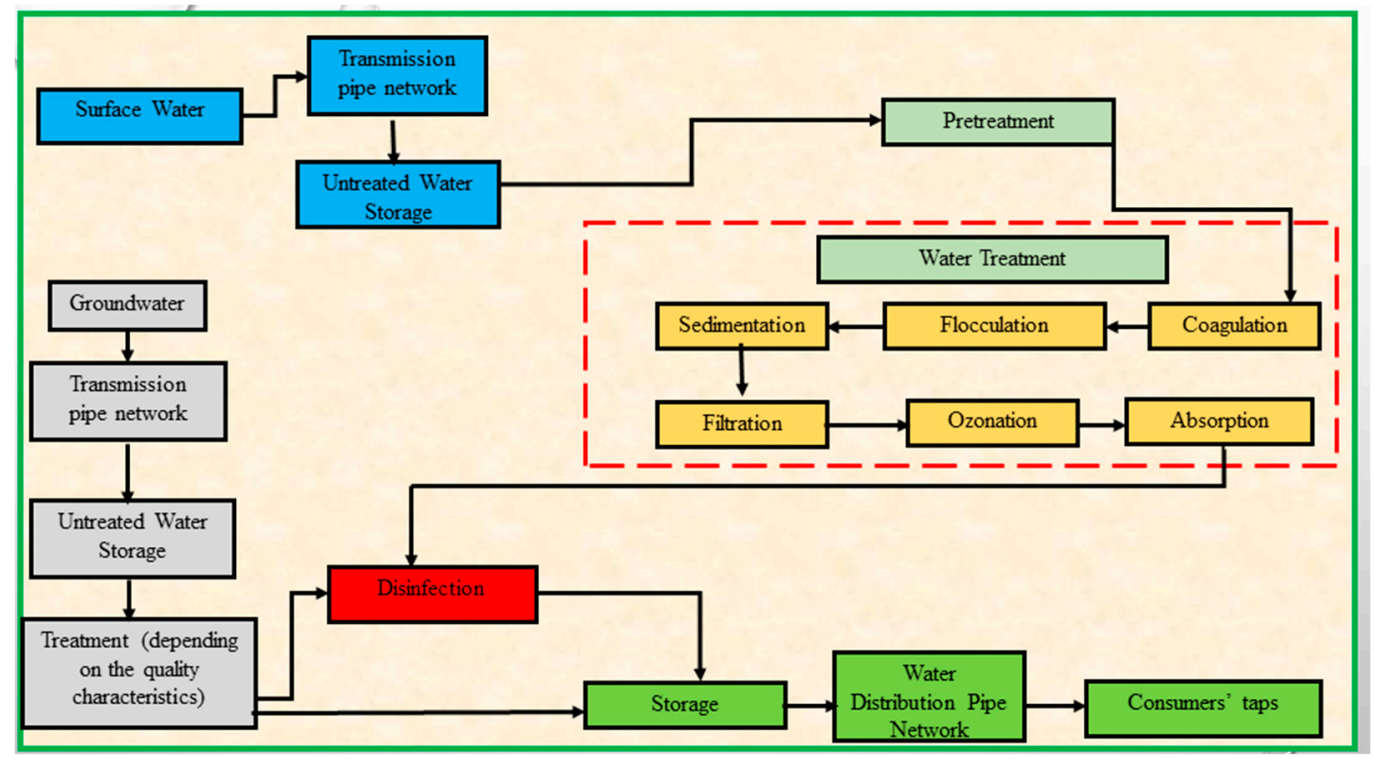

Figure 1. Typical flow diagram of a drinking water supply system (WSS).

The identification of all possible hazards in the WSS is a crucial procedure. In water intake points (regardless of water origin) physical, chemical, microbiological, and radiological hazards exist. Factors affecting the water parameters are geological characteristics, land uses, topography, etc. Both surface and groundwater can be contaminated because of inappropriate land uses, etc. Several foreign materials, such as wood, stones, etc., can also be found in the water. During water transmission through pipes, hazards include various pathogens, chemical residues, metallic objects, etc. In general, biofilm is formed in the water pipes, which is another factor affecting water quality. Pipes' material can also be a chemical hazard, as it is known that corrosion and pipes made of iron affect water quality. During water storage, the tanks' material can affect water characteristics, and several foreign objects may exist in the tanks. During the water treatment process, chemical hazards may exist due to the chemical processes that occur. These hazards depend on the processes taking place. Pathogens may also exist. During the disinfection stage, microbiological hazards tend to be 
eliminated, but chemical hazards occur. Disinfection-by-products, being chemical compounds having severe impacts on people's health, normally are formed during this process. In the storage and distribution of water, all kind of hazards are possible-foreign objects may exist, chemical compounds may be formed or exist (due to the various materials of the equipment) and pathogens exist (due to poor disinfection or other causes, such as microbe penetration due to leakages, etc.).

\section{Risk Assessment and Critical Control Points Identification}

To determine the critical control points in a WSS, risk assessment is elaborated. Every stage of the WSS is examined, taking into consideration the probability of occurrence of the risk as well as its severity. The methodology used is a semi-quantitative risk evaluation procedure, based on the implementation of food safety management systems [8] covering prerequisite programs and procedures based on HACCP principles. The risk level is defined based on the probability of the hazard's occurrence and the hazard's effect. As probability $(\mathrm{P})$, the probability of the hazard occurring in the end product is defined, if the specific control measures are not present or failing, taking into consideration the next process steps where hazard's elimination of reduction to an acceptable level is possible and taking into consideration the already implemented prerequisite programs. Probability takes values from 1 (very small) to 4 (high). Very small probability (value $=1$ ) means that: (a) The hazard has never occurred before; (b) there is a next step in the process that eliminates or reduces the hazard; (c) when the control measure fails, the production process is not possible; and (d) there is limited or local contamination [8]. The probability is small $(\mathrm{P}=2)$ when: (a) The prerequisite program fails or is not existing, the probability of the hazard occurring is limited; and $(b)$ the control measures are general and well implemented. Real probability $(P=3)$ means that when the control measure fails is not existing, and the hazard is present at the end-product [8]. Finally, when the control measure fails or is not existing, then the hazard is present, and the probability is high $(\mathrm{P}=4)$. The effect $(\mathrm{E})$ or severity of the hazard related to human health takes values from 1 (limited effect) to 4 (very serious effect) [8]. The effect is limited $(E=1)$ when there is no problem for the consumer related to food safety or the hazard does not reach a dangerous concentration. The effect is moderate $(E=2)$ when exposition to a high concentration for a long period of time results in no serious injuries, or the effect on health is temporary but clear. The effect is considered serious $(E=3)$ when: (a) There is a clear effect on health with short-term or long-term symptoms, rarely resulting in mortality; and (b) the hazard has a long-term effect, but the maximal dose is unknown [8]. Very serious effect $(\mathrm{E}=4)$ means that: (a) The consumer group belongs to a risk category and the hazard can result in mortality; (b) the hazard results in serious symptoms and mortality can result; and (c) there are permanent injuries [8]. The risk level (R) is estimated as follows: $\mathrm{R}=\mathrm{P} \times \mathrm{E}$, with a scale from 1 to 7 , as shown in Figure 2 [8]. When risk levels 1 and 2 are estimated, then no specific actions are necessary, and control is covered by prerequisite programs elaborated. When risk levels 3 and 4 are estimated, then it must be examined if the prerequisite programs monitor and control the identified risk. When risk levels are estimated to be 5, 6, and 7, a critical control point is identified [8].

\begin{tabular}{lcccc}
\hline High (4) & 4 & 5 & 6 & 7 \\
\hline Real (3) & 3 & 4 & 5 & 6 \\
\hline Small (2) & 2 & 3 & 4 & 5 \\
\hline Very small (1) & 1 & 2 & 3 & 4 \\
\hline & Limited (1) & Moderate (2) & Serious (3) & Very serious (4) \\
\hline
\end{tabular}

Figure 2. Determination of Risk (R) based on Probability (P) and Effect (E) [8].

Based on the methodology described above, the critical control points in a typical WSS are identified. During the water intake phase, physical hazard, due to foreign bodies is ranked in a very small probability (1) because the treatment process (filtration, etc.) will eliminate the probability, while there is a moderate effect (2) to the consumers' health. The risk level value, due to physical hazards, is 2 . Chemical hazards, due to the presence of heavy metals, industrial waste pollution, 
pesticides, etc., is 5 . The hazard's probability of occurring is real (3) as some of the chemical substances can be eliminated later during water treatment, but the hazard can still be present in treated water. The effect on human health is serious $(E=3)$. Biological hazards, due to of contamination of wastewater and waste, have a risk value of 5 . The probability of the hazard occurring is small (2) as further water treatment methods will inactivate the pathogens. However, the effect is very serious (4) for the consumers' health.

During water transmission to the reservoirs before treatment, physical hazards, such as the presence of foreign bodies (e.g., metals) have a low risk (2). The probability is very small (value 1) because foreign bodies will be removed during water treatment, and the effect is moderate (value 2) as there is no severe danger for the consumers' health. Chemical hazards, due to pipes' corrosion or other substances from the water intake, have a moderate risk (4). The probability of occurrence is small (2) as it is limited even if the control prerequisite programs fail or are not existing and the effect on the consumer's health is serious (3). Any pathogens present in the water will be inactivated later in the process, during disinfection, thus, the biological risk is moderate (3). Probability is very small (1) and the effect is very serious (4).

During untreated water storage, impurities (physical hazards) may be present in the water resulting in low risk (2). The probability is very small (1) as any foreign body will be removed during treatment and the effect is moderate (2). The risk due to chemical hazards (e.g., presence of chemical compounds from maintenance or cleaning work conditions) is moderate (3). The probability is limited, and therefore, very small (1), but the effect is serious (3) for the consumers' health. Biological hazards, due to pathogens presence, have a moderate risk (4), as the probability is very small (1) as disinfection takes place later in the process and the effect is very serious (4).

During the water treatment process, physical hazards exist as any foreign body may pass from the treatment phase, and the risk is moderate (3). The probability is small (2), while the effect is moderate (2). Chemical hazards, such as the added chemicals and the residuals, have a high risk (5). Probability of existence is real (3) as such chemical compounds, if formed, will be present in the water, and the effect on the consumers is serious (3). Pathogens may be present in this phase, causing a high risk (5). Probability is small (2), as disinfection takes place later, but the effects on human health are very serious (4). During groundwater treatment, chemical hazards exist having a high risk (5). The probability is real (3) and the effect is serious (3).

During treated water storage, the same physical, chemical and biological hazards exist as at the untreated water storage process. However, in this phase, the probability the physical hazard occurring is small (2) and the effect remains moderate (2). Thus, the risk of physical hazards is moderate (3). The probability the chemical hazard occurring is small (2) and the effect is serious (3), thus the risk for the chemical hazards is moderate (4). The risk for the biological hazards is high (5), as the probability is small (2) and the effects remain very serious (4). The disinfection process is studied separately, as it usually takes place in the water tank before the water enters the distribution network. Chemical hazards include the formation of disinfection-by-products, and the high dose of disinfectant added, having a high risk (6). The probability the hazard occurring is real (3) and the effects are very serious (4), especially when the concentrations of these compounds exceed the parametric values. Biological hazards exist in this phase when the pathogens are resistant to the disinfectant and the risk is high (6). The probability is real (3) and the effects are very serious for the consumers' health (4).

At the last phase of water distribution, physical hazards include the presence of metallic or nonmetallic bodies in the pipes and the risk is high (5). The probability is real (3) and the effects for the consumers' health are serious (3). Chemical hazards, such as chemical compounds formed within the distribution network from corrosion or other reactions that take place, have a high risk (5). The probability the chemical hazards occurring is real (3) and the effects on the consumers' health are serious (3). The biological hazards, such as the potential development of pathogenic microorganisms (due to poor maintenance conditions because of lack of disinfectant residual), have a high risk (6). The probability of occurrence is real (3) and the effects are very serious (4). Figure 3 shows the results of the implementation of the methodology. 


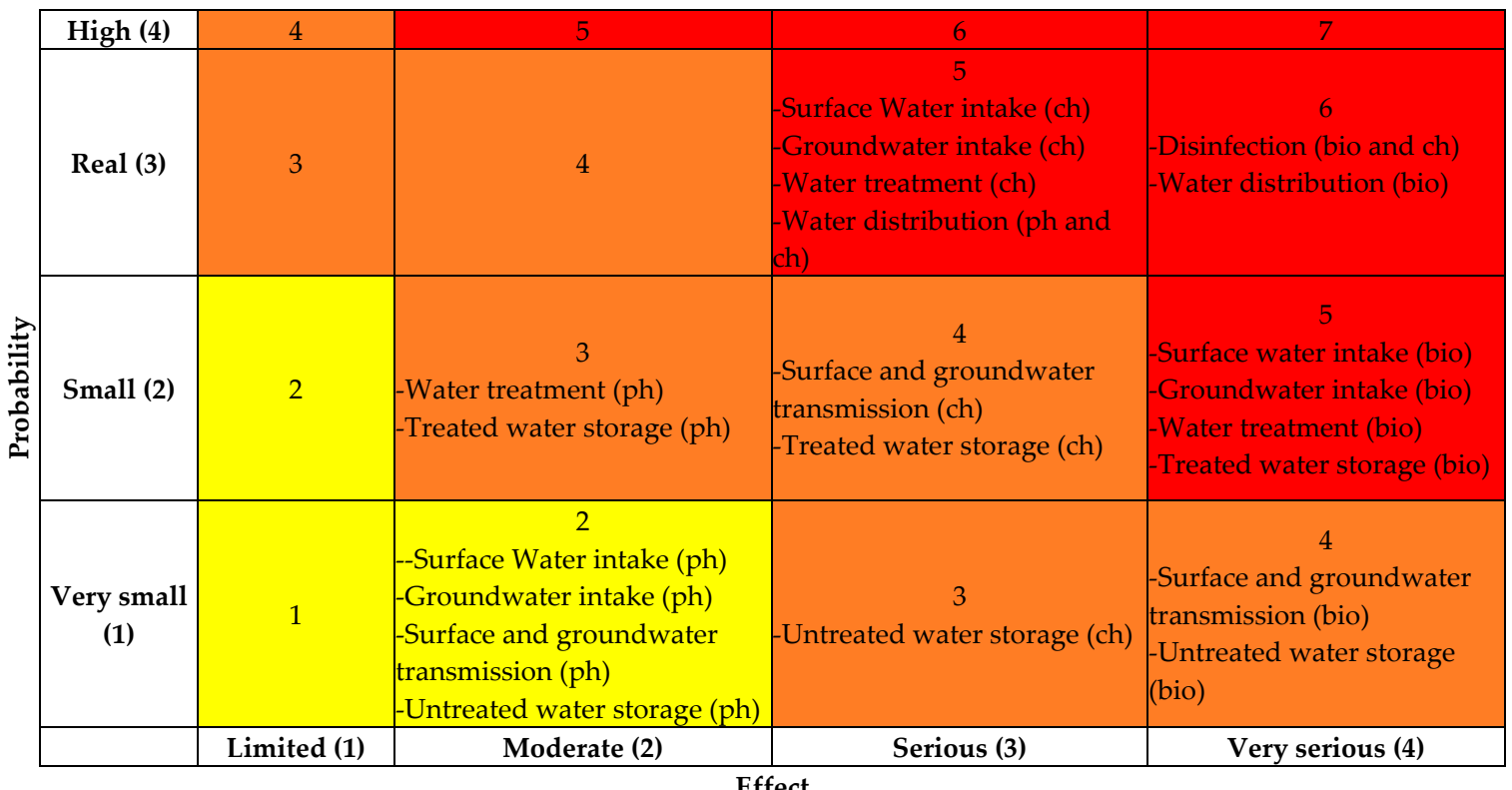

Figure 3. Determining the critical control points using the semi-quantitative risk evaluation methodology.

\section{Results and Discussion}

Thus, the methodology followed provides the critical control points, being the ones with a risk level of 5, 6, and 7 (Figure 3). The critical control points identified are (Table 1):

- Surface and groundwater intake points for chemical and biological hazards;

- Water treatment for chemical and biological hazards;

- Disinfection for chemical and biological hazards;

- Treated water storage for biological hazards;

- Water distribution for physical, chemical and biological hazards.

Table 1. Critical control points (CCP).

\begin{tabular}{ccc}
\hline Water Supply Phase & Hazard & CCP \\
\hline \multirow{2}{*}{ Surface water intake } & $\begin{array}{c}\text { Biological } \\
\text { Chemical }\end{array}$ & CCP1B \\
Groundwater intake & $\begin{array}{c}\text { Ciological } \\
\text { Chemical }\end{array}$ & CCP2B \\
& CCP2C \\
Water treatment & $\begin{array}{c}\text { Biological } \\
\text { Chemical }\end{array}$ & CCP3B \\
& CCPC \\
Disinfection & Biological & CCP4B \\
Treated water storage & Chemical & CCP4C \\
& Physical & CCP5B \\
Water distribution & CCP1P \\
& Chemical & CCP5C \\
& Biological & CCP6B \\
\hline
\end{tabular}

After determining the critical control points, the monitoring parameters, the monitoring systems and the corrective actions need to be determined. The monitoring parameters in water intake points are provided by the national (Joint Ministerial Decision 67322/Official Gazette B3282/19.09.2017) and European legislation (Directive 98/83/EC). These water quality parameters include odor, taste, etc.; several water physicochemical parameters, such as $\mathrm{pH}$, turbidity, conductivity, residual chlorine, etc.; and microbiological parameters, such as Escherichia coli, enterococci, etc. The monitoring system consists of periodic samplings which are determined in the legislation and are based on the water 
volume abstracted and the number of consumers served. Corrective actions include the elimination of the contamination sources, searching for alternative water intake points, prohibitive measures, design of protection zones, determination of land uses. In the water treatment phase, the monitoring parameters are water $\mathrm{pH}$, turbidity, total organic carbon (TOC) or other indicator showing the presence of organic matter and conductivity. The parametric values are given at the legislation and described in the literature [3,9-13]. Water $\mathrm{pH}$ values are lower than 8 , turbidity values are lower than 1 to $1.5 \mathrm{NTU}$, TOC values lower than $2 \mathrm{ppm}$ and conductivity values ranging from 750 to $2000 \mu \mathrm{S} / \mathrm{cm}$. The monitoring system is the sampling and monitoring of the water parameters. Corrective actions include change of chemicals' doses, $\mathrm{pH}$ adjustment, change of the chemical compounds used in the treatment phase, etc. [3,9-13].

During the disinfection phase, the monitoring parameters are water $\mathrm{pH}$, turbidity, residual chlorine, microbiological indicators and THMs concentrations [3,9-13]. The critical points are $\mathrm{pH}$ values lower than 8 , turbidity values lower than $1 \mathrm{NTU}$, residual chlorine concentration between 0.4 to $0.6 \mathrm{ppm}$, THMs concentrations lower than $100 \mu \mathrm{g} / \mathrm{L}$ and microbiological indicators values in compliance with the national and European legislation. The monitoring system consists of continuous sampling and monitoring of the parameters. Corrective actions include the change of disinfection dose, the change of disinfectant, re-chlorination in the water distribution network and the optimal location of disinfection boosters.

Regarding treated water storage, the monitoring parameters are water $\mathrm{pH}$, total coliforms, residual chlorine and water age $-\mathrm{pH}$ values are below 8 , there is no existence of total coliforms, residual chlorine values range between 0.5 to $0.8 \mathrm{ppm}$, and water age as low as possible. For water storage, the parameters' monitoring should be elaborated daily. Corrective actions include contamination checks and cleaning of the tanks and re-chlorination methods [3,9-13].

Finally, in the water distribution network, the monitoring parameters are residual chlorine concentrations within the network and particularly at the dead-ends, water $\mathrm{pH}, \mathrm{TOC}$, total coliforms, pressure, impurities and third-person access [3,9-13]. The critical points are $\mathrm{pH}$ values between 6.5 and 9.5, residual chlorine values ranging between $0.2-0.5 \mathrm{ppm}$, TOC within acceptable limits, nonexistence of total coliforms and adequate pressure of at least 2 bars. Impurities should not exist, and access to third-persons is denied. The parameters should be monitored frequently, while online monitoring is a highly effective measure. Corrective actions include the optimal location of disinfection boosters, immediate failures' repair and proactive maintenance, the establishment of an early warning system that interrupts water supply when critical parameters values exceed the maximum allowable ones [14] and provision of information to the customers. Table 2 summarizes the critical control points, the monitoring parameters and systems and the corrective actions necessary for the water supply phases.

\section{Conclusions}

This paper identified the vulnerable-critical control points of a water distribution network using the HACCP methodology. The critical control points during water intake, regardless of the water origin (surface or groundwater), are water treatment, disinfection, storage, and distribution. The hazards identified in these critical control points are mainly chemical and biological, while in distribution phase, all hazards (physical, chemical, biological) exist. Critical control points determination is a difficult task, and depends on each water supply system characteristics. This study can contribute to general guidelines as it does not study a specific water supply system. Implementation of the methodology to a specific water supply system should take the particular characteristics of the system under consideration. Based on this methodology, the monitoring parameters and the monitoring systems are also identified. Such parameters should follow the guidelines of the national and European legislation, and take into consideration the guidelines of the World Health Organization (WHO). 
Table 2. Monitoring parameters and system, CCP and corrective actions for all phases in a drinking WSS (based on [3,9-13]).

\begin{tabular}{|c|c|c|c|c|c|}
\hline $\begin{array}{l}\text { Water } \\
\text { Supply } \\
\text { Phase }\end{array}$ & Hazard & Monitoring Parameter & Critical Point & Monitoring System & Corrective Actions \\
\hline $\begin{array}{l}\text { Surface and } \\
\text { groundwater } \\
\text { intake }\end{array}$ & $\begin{array}{l}\text { Biological } \\
\text { (CCP1B and CCP2B) } \\
\text { Chemical } \\
\text { (CCP1C and CCP2C) }\end{array}$ & $\begin{array}{l}\text { Obligatory and indicative parameters of } \\
\text { the Directive } 98 / 83 / \mathrm{EC} \text { and JMD } \\
67322 / 2017\end{array}$ & $\begin{array}{l}\text { In compliance with the } \\
\text { Directive 98/83/EC }\end{array}$ & $\begin{array}{l}\text { Periodic chemical and } \\
\text { microbiological analyses }\end{array}$ & $\begin{array}{l}\text { - Elimination of the contamination source } \\
\text { - Alternative water intake source } \\
\text { - Prohibitive measures } \\
\text { - Development of protection zones } \\
\text { - Land use determination }\end{array}$ \\
\hline Treatment & $\begin{array}{l}\text { Biological } \\
\text { (CCP3B) } \\
\text { Chemical } \\
\text { (CCP3C) } \\
\end{array}$ & $\begin{array}{l}\text {-Turbidity } \\
\text {-TOC } \\
\text {-Conductivity } \\
\text {-pH }\end{array}$ & $\begin{array}{l}<1-1.5 \mathrm{NTU} \\
<2 \mathrm{ppm} \\
750-2000 \mu \mathrm{S} / \mathrm{cm} \\
<8\end{array}$ & $\begin{array}{l}\text { Continuous determination of the } \\
\text { parameters }\end{array}$ & $\begin{array}{l}\text { - Change of the chemicals' dose } \\
\text { - Change of mixing conditions } \\
\text { - Change of chemicals used } \\
\text { - pH adjustment }\end{array}$ \\
\hline Disinfection & $\begin{array}{l}\text { Biological } \\
\text { (CCP4B) } \\
\text { Chemical } \\
\text { (CCP4C) }\end{array}$ & $\begin{array}{l}\text {-pH } \\
\text {-Turbidity } \\
\text {-Residual chlorine } \\
\text {-Microbiological indicators } \\
\text {-THMs }\end{array}$ & $\begin{array}{l}<8 \\
<1 \mathrm{NTU} \\
0.4-0.6 \mathrm{ppm} \\
\text { In compliance with Dir. } \\
98 / 83 / \mathrm{EC} \\
<100 \mu \mathrm{g} / \mathrm{L}\end{array}$ & $\begin{array}{l}\text { Continuous determination of the } \\
\text { parameters }\end{array}$ & $\begin{array}{l}\text { - Change of disinfectant dose } \\
\text { - Change of disinfectant } \\
\text { - Re-chlorination inline } \\
\text { - Optimal location of disinfection boosters }\end{array}$ \\
\hline $\begin{array}{l}\text { Treated } \\
\text { water storage }\end{array}$ & $\begin{array}{l}\text { Biological } \\
\text { (CCP5B) }\end{array}$ & $\begin{array}{l}\text {-pH } \\
\text {-Total Coliforms } \\
\text {-Residual chlorine } \\
\text {-Water age }\end{array}$ & $\begin{array}{l}<8 \\
\text { Non-existence in } 100 \mathrm{~mL} \\
0.5-0.8 \mathrm{ppm} \\
\text { As low as possible }\end{array}$ & $\begin{array}{l}\text { Everyday determination of the } \\
\text { parameters }\end{array}$ & $\begin{array}{l}\text { - Re-chlorination } \\
\text { - Storage tanks contamination checks } \\
\text { - Storage tanks cleaning }\end{array}$ \\
\hline $\begin{array}{l}\text { Distribution } \\
\text { network }\end{array}$ & $\begin{array}{l}\text { Physical } \\
\text { (CCP1P) } \\
\text { Chemical } \\
\text { (CCP5C) } \\
\text { Biological } \\
\text { (CCP6B) }\end{array}$ & $\begin{array}{l}\text {-Residual chlorine in the network and } \\
\text { at consumers' taps } \\
\text {-pH } \\
\text {-TOC } \\
\text {-Total Coliforms } \\
\text {-Pressure } \\
\text {-Impurities } \\
\text {-Third-persons access }\end{array}$ & $\begin{array}{l}0.2-0.5 \mathrm{ppm} \\
6.5-9.5 \\
\text { Within acceptable limits } \\
\text { Non-existence in } 100 \mathrm{~mL} \\
>2 \text { bar } \\
\text { Non-existence } \\
\text { Denied }\end{array}$ & $\begin{array}{l}\text { Frequent determination of the } \\
\text { parameters } \\
\text { Online monitoring }\end{array}$ & $\begin{array}{l}\text { - Optimal location of disinfection boosters } \\
\text { inline } \\
\text { - Failures' repair and proactive maintenance } \\
\text { - Distribution network cleaning } \\
\text { - Automated water supply interruption when } \\
\text { critical parameters values exceed critical limits } \\
\text { - } \quad \text { Rejection of unsuitable water quality } \\
\text { - Informing consumers }\end{array}$ \\
\hline
\end{tabular}


Corrective actions were also determined in this article. Advanced technological tools must be used, such as disinfection boosters located in an optimal way within the water distribution system, online monitoring for chemical and microbiological parameters, and early warning systems. This will monitor the system, and provide alerts in cases when the parameters' values exceed their allowable limits [14].

An effective vulnerability assessment can serve as a guide to the water utility by providing a prioritized plan for security upgrades, modifications of operational procedures, and/or policy changes to mitigate the risks and vulnerabilities to the utility's critical assets.

Author Contributions: Conceptualization, methodology, analysis, writing S.T.; supervision, V.K. All authors have read and agree to the published version of the manuscript.

Funding: The research is elaborated within the framework of the invitation "Granting of scholarship for PostDoctoral Research" of the University of Thessaly, which is being implemented by the University of Thessaly and was funded by the Stavros Niarchos Foundation.

Acknowledgments: The research is elaborated within the framework of the invitation "Granting of scholarship for Post-Doctoral Research" of the University of Thessaly, which is being implemented by the University of Thessaly and was funded by the Stavros Niarchos Foundation.

Conflicts of Interest: The authors declare no conflict of interest.

\section{References}

1. WHO. Guidelines for Drinking-Water Quality, 4th ed.; World Health Organization: Geneva, Switzerland, 2011.

2. Tsitsifli, S.; Tsoukalas, D. Water Safety Plans and HACCP implementation in water utilities around the world: Benefits, drawbacks and critical success factors. Environ. Sci. Pollut. Res. 2019, doi:10.1007/s11356019-07312-2.

3. Nadebaum, P.; Chapman, M.; Morden, R.; Rizak, S. A Guide to Hazard. Identification \& Risk Assessment for Drinking Water Supplies; Research report II; CRC for Water Quality and Treatment: Salisbury, Australia, 2004.

4. Tsitsifli, S.; Kanakoudis, V. Disinfection impacts to drinking water safety-A review. Proceedings 2018, 2, 603, doi:10.3390/proceedings2110603.

5. Tsitsifli, S.; Kanakoudis, V. Developing THMs' predictive models in two water supply systems in Greece. Water 2020, 12, 1422, doi:10.3390/w12051422.

6. Reynolds, A.K.; Mena, D.K.; Gerba, P.C. Risk of Waterborne Illness via Drinking Water in the United States. In Reviews of Environmental Contamination and Toxicology. Reviews of Environmental Contamination and Toxicology; Whitacre, D.M., Ed.; Springer: New York, NY, USA, 2008; Volume 192, pp. 117-158.

7. Ashbolt, J.N. Microbial Contamination of Drinking Water and Human Health from Community Water Systems. Curr. Environ. Health Rep. 2015, 2, 95-106.

8. Commission Notice on the Implementation of Food Safety Management Systems Covering Prerequisite Programs (PRPs) and Procedures Based on the HACCP Principles, Including the Facilitation/Flexibility of the Implementation in Certain Food Businesses (2016/C 278/01). Available online: https://eurlex.europa.eu/legal-content/EN/TXT/PDF/?uri=CELEX:52016XC0730(01)\&from=EL (accessed on 10 June 2019).

9. Damikouka, I.; Katsiri, A.; Tzia, C. Application of HACCP principles in drinking water treatment. Desalination 2007, 210, 138-145.

10. Havellar, A.H. Application of HACCP to drinking water supply. Food Control. 1994, 5, 145-152.

11. Khaniki, G.R.J.; Mahdavi, M.; Mohebbi, M.R. HACCP application for treatment of drinking water for Germi in Iran. J. Food Agric. Environ. 2009, 7, 709-712.

12. Martel, K.; Kirmeyer, G.; Hanson, A.; Stevens, M.; Mullenger, J.; Deere, D. Application of HACCP for Distribution System Protection; American Water Works Association: Denver, CO, USA, 2006. 
13. Tavasolifar, A.; Bina, B.; Amin, M.M.; Ebrahimi, A.; Jalali, M. Implementation of hazard analysis and critical control points in the drinking water supply system. Int. J. Environ. Health Eng. 2012, 1, 32, doi:10.4103/22779183.99334.

14. Kanakoudis, V.; Tsitsifli, S. Potable water security assessment-A review on monitoring, modelling and optimization techniques applied to water distribution networks. Desalin. Water Treat. 2017, 99, 18-26. 